\title{
EXISTING AND NOVEL THERAPIES FOR PSORIASIS
}

\author{
CH. NAGA NAVYA ${ }^{1}$, GAURAV K JAIN ${ }^{2}$, VIKAS JAIN ${ }^{1 *}$
}

${ }^{1}$ Department of Pharmaceutics, J.S.S College of Pharmacy, Mysore, Karnataka, India. ${ }^{2}$ Department of Pharmaceutics, School of Pharmaceutical Education and Research, Jamia Hamdard, New Delhi India. *Email: vikasjain@jssuni.edu.in

Received: 10 July 2018, Revised and Accepted: 05 September 2018

ABSTRACT

Psoriasis is adjudged as prototypic papulosquamous skin condition attributed by the erythematous papules (or) plaques. It occurs at any age but commonly seen in age groups of 20-30 and 50-60 years. Psoriasis affects around 2\% of the world population. Psoriasis has a broad spectrum of skin indications occurring in different forms with common characteristics. It is clinically classified as non-pustular and pustular psoriasis. Existing therapies include topical therapy, systematic therapy, and phototherapy. Biological drugs and novel immunological factors have been identified as alternative therapy to conventional therapies. These biological drugs show more efficacies with fewer side effects in long-term application.

Keywords: Psoriasis, Biological therapy, Anticytokine therapy, Phototherapy.

(C) 2018 The Authors. Published by Innovare Academic Sciences Pvt Ltd. This is an open access article under the CC BY license (http://creativecommons. org/licenses/by/4. 0/) DOI: http://dx.doi.org/10.22159/ajpcr.2018.v11i12.27383

\section{INTRODUCTION}

Psoriasis is characterized by papulosquamous skin condition with erythematous papules (or) plaques. Dysregulation of the immune system leads to red, scaly, flaky, chronic inflammatory, and itchy patches with increased keratinocytes proliferation [1]. Sometimes, the body's immune system cannot differentiate between the foreign particle and its own. During the process of defending itself against infection, it may lead to excessive skin cell proliferation. Psoriatic arthritis refers to psoriasis that affects the joints. The severity of psoriasis varies among individuals of different age groups. Psoriasis impacts patient's psychological stress due to its appearance. This stress may trigger psoriasis even more which might worsen the condition at times. Psoriasis is prevalent in $2 \%$ population around the world, mainly seen in the age groups of 20-30 and 50-60 years. Plaque psoriasis is prevalent among $80 \%$ of individuals, of which around $33 \%$ suffers from mild diseases and remaining from moderate-to-severe conditions $[1,2]$

\section{TYPES OF PSORIASIS}

Psoriasis is classified into a broad spectrum of skin indications. It is generally divided into pustular and non-pustular forms. A person can represent different forms of psoriasis at the same time. It can affect any part of the body. However, all forms show common characteristics like erythema with thickened scales, and the size of lesions varies from a pinhead to $20-\mathrm{cm}$ diameter. These lesions may appear oval, polycyclic, or round in shape [Table 1] [3,4].

\section{Psoriasis vulgaris}

About $90 \%$ of cases are noticed as psoriasis vulgaris in clinical form. It appears as erythematous plaques which are covered by silver scales. Lesions distribute symmetrically and frequently occur on the knees, scalps, sacral region, and elbow. If psoriatic plaques surface is scraped with a blunt scalpel, flakes fall off as layers and it exhibits a phenomenon called as "wax spot phenomenon." Further scrapping discloses a wet layer attached to the lesion, and this is the last layer of dermal papillae which is referred as "last membrane phenomenon." If it is scraped further, an erythematous background and bleeding foci which look like red pinpoints referred as "Woronoff ring" are observed. There is no clarified pathogenesis for this ring. However, it may be due to a reduced level of prostaglandins in healing lesions [5-8].

\section{Guttate psoriasis}

It is mostly seen in children and young adults. The lesions structurally look like small droplets and rarely convert into squamous psoriatic papules. It usually manifests after a streptococcal infection. It is generally linked with HLA-Cw6 gene. These types of psoriasis occur on the trunk, proximal part of extremities, scalp, and face. They usually revert within 3-4 months, but in rare cases, it develops into plaques [9].

\section{Erythrodermic psoriasis}

Nearly $80 \%$ of the lesions that affect body surface are categorized as a generalized form of psoriasis, plaques, and papules which lose their attributes. Desquamation is not so definite, but it causes protein loss as well as some systematic problem such as edema of lower extremities, and cardiac, hepatic, and renal failure. Damage of skin barrier results in systematic reactions, which in turn leads to the development of psoriasis vulgaris or erythrodermic psoriasis [10].

\section{Palmoplantar psoriasis}

In general, palmoplantar psoriasis occurs on palms, hands, and soles of the feet. It affects more on thenar regions than the hypothenar region. Usually, erythema does not appear, but incase if it exists, then it appears as pinkish yellow lesions. Scales are the main lesions, and thick flakes may provide an appearance of keratoderma [11].

\section{Inverse psoriasis}

Inverse psoriasis or flexural psoriasis is localized in skin folds. Scaly lesions do not form because of friction and moisture produced between the skin folds. This form of psoriasis is diagnosed with fissured plaques. It is commonly observed in obese individuals with a tendency to develop a seborrheic lesion. This type of psoriasis refuses to accept classical therapy [10].

\section{Generalized pustular psoriasis}

It is the rare form of psoriasis with pustules, usually observed in young individuals. It either develops independently or seen as a complication of psoriasis vulgaris. In this form, leukocytosis, lymphopenia, and nitrogen balance will be increased. Within few days, pustules get dried, and new pustules arise within no time. Peripustular erythema has behavior to spread which leads to erythrodermia. The disseminated region should be promptly treated;otherwise, acute phase may cause to the fatal course [10-12]. 
Table 1: Clinical classification of psoriasis

Non-pustular psoriasis

Psoriasis vulgaris

Guttate psoriasis

Erythrodermic psoriasis

Palmoplantar psoriasis

Inverse psoriasis

\section{Impetigo herpetiform}

This type of psoriasis is rarely seen, referred to as generalized pustular psoriasis of pregnancy. It contains erythematous lesions with pustules. It involves mucous membrane and onycholysis secondary to subungual pustules. The lesions cause itching or burning sensation with a foul odor. It also shows some additional symptoms such as fever, shivering, nausea, and vomiting. It is related with hypocalcemia. Commonly, it occurs during subsequent pregnancies.

\section{Localized pustular psoriasis}

It is subdivided into two forms as Barber's-Pustular psoriasis and Acrodermatitis continua of hallopeau.

\section{Barber's-pustular}

In general, it is found in women with a family history of palmoplantar pustulosis. It is chronic, with 2-4 mm sized pustules which are located on the palmoplantar region. Its etiology is merely known. This disease is triggered by smoking, tonsillitis, humidity and high temperature.

\section{Acrodermatitis continua of hallopeau}

It comes under skin disorder which contains sterile pustular eruption located on figures and toes. It involves loss of nails and distal phalanges in severe conditions. Pustules join together to form small, polycyclic, purulent, fluid-filled vesicles [13].

\section{PSORIATIC ARTHRITIS (PSA)}

Its prevalence varies between 5.4 and $7 \%$ among patients. Pustular psoriasis prevalence ratio rises to $30-40 \%$ during psoriatic arthritis condition. During the onset of the second or third decade of the life of an individual, uncomplicated psoriasis begins and prevalence of psoriatic arthritis increases in the third decade. Psoriatic arthritis divided into five subgroups by "Moll and Wright" based on clinical form as classical PsA, asymmetric oligoarticular arthritis, symmetric polyarticular arthritis, arthritis mutilan, and spondylitic form [14,15].

Classical PsA is observed in mere $10 \%$ of individuals. It affects distal interphalangeal joints of the hands and feet. Asymmetric oligoarticular arthritis appears in 11\% of cases, and it affects major joints such as knee joints and proximal and distal interphalangeal joints. It also shows the symmetrical effect on the metacarpophalangeal and metatarsophalangeal joints. Symmetric polyarticular form looks similar to rheumatoid arthritis, while arthritis mutilan is distinguished by progressive osteolysis of phalangeal and metacarpal bones. In general, it appears on the hands, but sometimes, its presence can be observed on the feet with similar involvement. Spondylitic form is linked with peripheral arthritis, where the involvement of spondylitic joints and symmetric or asymmetric sacroiliac joint is seen.

\section{PATHOPHYSIOLOGY}

Cathelicidin belongs to AMP family in the skin which shows various immune regulations. Cathelicidin (LL-37 form) and DNA-complex together activates plasmacytoid dendritic cell. During psoriatic conditions, human cathelicidin peptide, especially active form of LL37 , is overproduced and aggregates with self- DNA, which leads to the formation of stable complexes. These stable complexes are recognized by plasmacytoid dendritic cell through TLR9 in the dermis. Thus, activated plasmacytoid dendritic cell releases interferon alpha and beta (INF- $\alpha$ and INF- $\beta$ ) which triggers local maturation of myeloid dendritic cell. These myeloid dendritic cells activate T-cells which are differentiated into T-helper (th1 and th17), which leads to autoreactive inflammation in psoriasis [16].

\section{TOPICAL PSORIASIS THERAPY}

\section{Corticosteroids}

In topical psoriasis treatment, corticosteroid remains a mainstay. Its mechanism is not precisely known. It acts as an anti-inflammatory, immunosuppressive, and anti-proliferative agent by showing influence on gene transcription. Due to its occlusive property, ointments are more effective. Its efficacy depends on skin type and plaque thickness [17,18]. Fluocinonide $(0.005 \% \mathrm{w} / \mathrm{v}$ as solution/foam), clobetasol (as $0.005 \% \mathrm{w} / \mathrm{v}$ shampoo/spray), hydrocortisone $(1 \% \mathrm{w} / \mathrm{v})$, and betamethasone $(0.005 \% \mathrm{w} / \mathrm{v})$ are most commonly employed active agents under this category.

\section{Vitamin D analogs}

In the treatment of psoriasis, Vitamin D analogs such as calcitriol, calcipotriol, and tacalcitol are involved. In some patients, monotherapy of Vitamin D analogs is effective, whereas the combination therapy (corticosteroid and Vitamin D analog) shows better efficacy. In the United States, calcipotriene was used as topical Vitamin D analog until 2009 , in the form of a cream, ointment, foam, or solution. In Europe, the topical Calcitriol ointment is being used, as it shows less irritation when compared with calcipotriene $[19,20]$.

\section{Calcipotriene}

Calcipotriene is also referred as ,calcipotriol and it is accepted therapy for psoriasis. Its mechanism is not precisely known, but it mainly shows its efficacy on hyperproliferation of keratinocytes, and it also shows efficacy on immune modulation, but it does not show outstanding results in psoriasis therapy. Combination therapy (corticosteroid and calcipotriene) depicts a rise in clinical response. Combination of calcipotriene with betamethasone propionate $(0.064 \%)$ shows more efficacy than monotherapy. Corticosteroid and calcipotriene are generally applied twice a day, individually however, a combination of these two drugs is administered only once in a day. As calcipotriene becomes inactive in the presence of acidic moieties and some corticosteroid are acidic in nature, owing to which the data related to controlled clinical trial are very sparse to claim the rationale behind the usage of combination therapy. However, a combination therapy had reasonable approaches when patients used both calcipotriene and corticosteroid at different times, once daily. Adverse effects are generally minimal a part of skin irritation [21,22].

\section{Calcitriol}

Calcitriol mechanism resembles calcipotriene, which shows efficacy on hyperproliferation of keratinocytes and inhibits inflammatory mediator. In a controlled study, perilesional erythema, perilesional edema, and burning sensation were reduced in calcitriol-treated areas [23,24].

\section{Tar}

The popularity of psoriasis therapy with tar is now reduced because of the availability of some new therapies. Its mechanism is not clearly known, but it acts as an antiproliferative agent. Tar can also be used with topical corticosteroid. However, it is not commercially available. Tar can be used without a prescription and is available in the form of shampoo, cream, lotion, oils, ointments, solution, and foam. In general, $2-3 \%$ of tar with $0.1 \%$ of triamcinolone cream can be applied twice per day to treat plaques. $1 \%$ of tar in fatty acid based lotion shows more efficacy than $5 \%$ conventional tar, and this $1 \%$ tar lotion resembles calcipotriene, efficacy wise. Tar produces unpleasant odor and it also tends to be messy $[25,26]$.

\section{Tazarotene}

Tazarotene is safe and effective topical retinoid used in psoriasis therapy. $0.1 \%$ cream is more effective than $0.05 \%$, but it causes some local adverse effects. As absorption of Tazarotene is minimal, systemic toxicity is unlikely to even in long-term therapy. Application 
of tazarotene for 20 min followed by washing causes less irritation compared with traditional use $[27,28]$.

\section{Calcineurin inhibitor}

$0.1 \%$ of topical tacrolimus and $1 \%$ pimecrolimus have good efficacy in treating facial and intertriginous psoriasis, and it is well tolerated too. Application of $0.1 \%$ pimecrolimus twice a day shows almost clearance of lesion. However, when compared to corticosteroids, it is less efficacious [29-31].

\section{Anthralin}

Since the early $20^{\text {th }}$ century, topical anthralin is used for psoriasis therapy and it has good efficacy. Its mechanism of action is not clearly known, but it has an anti-inflammatory effect and antiproliferative effect. Adverse effects of anthralin are skin irritation and red-brown stains which are temporary. The therapy starts with low concentration like $0.1 \%$ or $0.25 \%$ for $10-20 \mathrm{~min}$ application per day for minimal skin irritation and slowly increased until it reaches to contact time of $1 \mathrm{~h}$. Then, slowly, the concentration of anthralin is increased on the basis of lesion response and tolerance of the patient. In the United States, $1 \%$ or $2 \%$ cream and shampoo of anthralin is commercially available. Application time is usually 5-10 $\mathrm{min} /$ day, which is gradually increased up to 20-30 $\mathrm{min}$ depending on the tolerance of patient. The normal skin should not get in contact with anthralin as it causes skin irritation. We can protect unaffected skin by identifying plaques or by applying petroleum or zinc oxide to the unaffected skin before anthralin application [32-34].

\section{PHOTOTHERAPY}

\section{Ultraviolet (UV) light}

Psoriasis can be controlled using ultraviolet light. It acts as antiproliferative and anti-inflammatory agent. For this therapy, taking advice from a trained dermatologist is important. According to AAoD, UV-B radiation (290-320 nm) can be administered as monotherapy or in combination with tar. The inducing dose of UVB for patients should be weekly 3 times. Once it achieves remission, maintain the regimen which is recommended to prolong the remission [35]. Narrowband UV-B having a range of $311 \mathrm{~nm}$ is an alternative standard for psoriasis therapy apart from broadband 290 to $320 \mathrm{~nm}$. Narrowband UV-B dose shows more efficacy than broad brand UV-B dose to clear plaque psoriasis and apoptosis [36,37]

UV-A radiation or photochemotherapy (PUVA) warrants strict medical supervision. As compared to UV-B, UV-A can go deeper into dermis without causing any skin burn. This therapy involves either oral or topical (bath) administration of psoralen. If a patient undergoes oral therapy, then photosensitizing drug, 8-methoxy-psoralen is injected in patient followed with UVA exposure for $2 \mathrm{~h}$. This process happens thrice a week until dose increment gets remission. Later, recommended dose should be maintained either twice or once weekly. If a patient undergoes bath PUVA, then affected area of a patient is soaked for 1530 min in psoralen mixed with water before UVA exposure [38].

Photoprotection such as sunscreen, hat, and sun protective goggles is used pre- and post-treatment to avoid skin and ophthalmic injuries due to the exposure to UV rays. As emollients inhibit UV penetration into the skin, it should not be applied to the skin before treatment.

\section{Home phototherapy}

Home phototherapy (or) home UV-B is alternative method for officebased phototherapy. This method should be followed only when the clinician suggest it to follow by your own. Excessive use of this device should not be practiced, and it should not exceed the number of treatment that is prescribed by clinician. To avoid overexposure, electronic control is equipped with home phototherapy devices, which allows only prescribed numbers of therapies [39].

\section{Excimer laser}

Excimer laser at a range of $308 \mathrm{~nm}$ produces high energy. This is another method with a higher dose of UV-B involvement in the treatment of only affected skin. It gives faster results when compared with conventional phototherapy. Application of this therapy shows erythema and blistering. However, it can be tolerated easily and it has not been considered as major side effect by patients. UV-induced hyperpigmentation (tanning) is caused by excimer laser, but it can be controlled after termination of therapy $[40,41]$.

\section{Saltwater bath}

It is proved that natural sunlight with sea water combination can also treat psoriasis. Hence, salt water bath with artificial ultraviolet exposure is being used for treating psoriasis. Additional factual studies are needed to establish the potential of the said therapy for full-fledged application [42].

\section{SYSTEMIC THERAPY}

\section{Methotrexate}

Since 50 years, folic acid agonist methotrexate is used to treat psoriasis and it also shows efficacy for psoriasis arthritis and psoriatic nail disease. Initially, its mechanism of action was centered on antiproliferation, but later, it was considered as immunosuppressive agent, evidenced by the latest studies. It shows efficacy on activated T-cell which helps in the treatment of psoriasis. Methotrexate shows less efficacy compared to adalimumab. Methotrexate is recommended to be administered once weekly through oral, intravenous, intramuscular, or subcutaneous routes, and the range of administration is 7.5-25 mg/week [43-45].

\section{Retinoids}

Severe psoriasis can be treated with systemic retinoids. It also treats pustular and erythrodermic form. HIV-associated psoriasis patients also get treated with systemic retinoids. Acitretin is the retinoid used to treat psoriasis within the dose range of $25-50 \mathrm{mg} /$ day. Good results are seen when acitretin is used in combination with phototherapy. Adverse effect associated with retinoids therapy is cheilitis and alopecia [46-49].

\section{Calcineurin inhibitor}

Severe instances of psoriasis are treated with cyclosporine, a calcineurin inhibitor. It acts as T-cell suppressor and administered in the dose range of 3-5 mg/day, orally. Within 4 weeks of treatment, massive improvements in patient's condition can be seen. However, long-term use of cyclosporine results in renal toxicity and hypertension [50-52].

\section{Apremilast}

Moderate-to-severe plaques are treated with apremilast. It acts as phosphodiesterase-4 inhibitor which helps in decreasing the production of multiple cytokines which cause psoriasis pathogenesis. The therapeutic dose of apremilast is $30 \mathrm{mg}$ twice per day; however, it is considered to be less efficacious when compared with cyclosporine, ustekinumab, and anti-tumor necrosis factor (TNF) therapies [53-57].

\section{NOVEL THERAPIES}

Anti-TNF therapy

TNF- $\alpha$ (a cytokine) induces inflammation in psoriasis by involving multiple pathways. It raises adhesion molecules on the vascular endothelial cell that facilitates inflammatory cells into lesion. It also stimulates keratinocyte of other pro-inflammatory mediators and activates dendritic cell and macrophages. Recent studies suggested that TNF- $\alpha$ inhibitors play a major role in the treatment of psoriasis [58].

TNF- $\alpha$ gets neutralized by infliximab. As it binds to TNF- $\alpha$ and permanently gets it deactivated, it helps in the inhibition of inflammatory cytokine production and relieves from the symptoms of psoriasis $[59,60]$. Adalimumab and certolizumab pegol are absolutely humanized monoclonal antibodies explored for the management of psoriasis, currently available in the market, administered every 2 weeks. They do exhibit the same mode of action as that of infliximab.

Synthetic receptors such as etanercept have higher empathy for TNF- $\alpha$ as compared to natural receptors. This high binding affinity results in neutralization of TNF- $\alpha$-mediated psoriatic inflammation. It can be administrated twice a week [61-63]. 


\section{Other anticytokine therapy}

Pro-inflammatory cytokines are a mediator for various biological processes, and it gets stimulated in the body by increasing the level of cytokines that lead to many pathologies, autoimmunity, and cancer. These anticytokines block the antibodies and neutralize the cytokines [64].

\section{Ustekinumab}

Dendritic cells produce two interleukin subunits, interleukin (IL)-23 and IL-12, which play a role in pathology. This Ustekinumab binds to IL-23 and IL-12 which inhibits signal transduction pathways and shows differences in T-cell as Th1 and Th17. Hence, IL-23 and IL-12 blockage leads to reducing the number of Th1 and Th17 in the blood [65].

\section{Apilimod}

In myeloid leukocytes synthesis, IL-12 and IL-23 get suppressed by Apilimod, which is developed from triazine derivative. Recent studies proved that apilimod not only inhibits IL-12 and IL-23 but also multidownstream cytokines in the affected skin and increased synthesis of IL-10, an anti-inflammatory cytokine $[66,67]$.

\section{Brodalumab}

IL-17 plays a major role in the survival of the psoriatic disease. Brodalumab acts as human anti-IL-17 receptor which suppresses the efficacy of IL-17A, IL-17F, and IL-17A/F [68].

\section{Ixekizumab}

Ixekizumab is a novel human monoclonal antibody. IgG4 acts as antiIL17 by blocking cytokines, beta-defensins, and antimicrobial peptides production in keratinocytes. It also suppresses chemokines which are responsible for skin lesions. Moderate-to-severe plaques psoriasis can be treated by Ixekizumab [69].

\section{Alefacept}

LFA-3, which is expressed on antigen presenting cell, binds to CD2 molecule and results in the production of mature T-cell and natural killer cells. Hence, this LFA-3 with CD2 molecule will produce a signal that results to the activation of naïve T-cell in effector cell. Alefacept blocks the interaction between CD2 molecule and LFA-3 and, hence, prevents T-cell activation and proliferation [70,71].

\section{Small molecule inhibitor}

Small molecules inhibitors serve as better alternatives to treat psoriatic conditions which remain untreated with conventional therapies. These agents assist in inhibiting signaling pathways that help in eliciting inflammatory cytokines [72]. Different categories of therapeutic agents are being discussed here.

\section{Phosphodiestrase-4 inhibitor}

T-cell secretes inflammatory cytokines such as IFN- $\gamma$, TNF- $\alpha$, and IL12 from monocytes in blood. Inhibition of phosphodiesterase helps in suppressing T-cell secretion [53,73-75].

\section{Protein kinase inhibitor}

Protein kinase $\mathrm{C}$ inhibition helps to inhibit classical and novel protein kinase $\mathrm{C}$ which regulates immune signaling cascade and INF- $\gamma$ and IL17 production $[75,76]$

\section{Mitogen-activated protein kinase inhibitor}

Different inflammatory diseases have been chronicled the importance of nitrogen-activated protein kinase. It shows involvement in cell proliferation, inflammation, and differentiation. p38-MAPK is over expressed in psoriatic lesions and BMS582949 is identified as a novel selective p38-MAPK inhibitor [77,78].

\section{Janus kinase inhibitor}

Several cytokines receptors are connected with Janus kinase which belongs to cell-signaling molecules. Janus kinase activates STAT pathway which controls the expression of a nuclear target in gene and induces pro-inflammatory gene. JAK3 shows involvement in IL-2, IL-6, IL-7, IL-15, and IL-21 signaling. Tofacitinib inhibits the JAK1 and JAK3. ASP015K4 and VX-509 inhibit JAK3, and INCB28050 inhibits JAK 1 and JAK2 [79,80].

\section{Nerve growth factor inhibitor}

Large quantities of neuropeptides are released by sensory nerve fiber due to stress. Research also proved the link between emotional stress and peripheral nervous system, resulting in the onset of psoriasis lesion. T-cell activation, keratinocytes proliferation, angiogenesis, and cutaneous nerve proliferation have been activated by nerve growth factors which are present in psoriatic lesional and non-lesional plaques. K252a and CT327 act as NGF inhibitors and available as topical therapy.

\section{OTHER THERAPIES}

\section{Insulin}

In dermis, IL- $1 \beta$ is present in a large amount which activates P38-MAPK (mitogen-activated protein kinase). This kinase acts on insulin receptor and induces the insulin resistance in the keratinocytes, which in turn alters keratinocytes proliferation and differentiation and subsequent alleviation of symptoms related to psoriasis.

\section{Magnetic therapy}

The use of magnetic therapy with low frequency for psoriasis therapy helps for the treatment of both skin and joint manifestation. Magnetic therapy acts as anti-inflammatory for healing, soothing, reducing itch, immunostimulator, and detoxification effects. When both active periods of skin lesion and remission phase are present, this magnetic therapy is used. The affected area is attached with applicator, beneficial to liver and stomach therapy by supporting liver detoxification, metabolic function, and absorption process and adjusting the digestion. Depending on the development and course of disease, application of therapy will be given repeatedly (or) throughout sufferer lifetime.

\section{CONCLUSION}

Psoriasis is persistent, familial, non-communicable skin disease, with no precise cure. A constellation of therapy is available which can control the disease of psoriasis among people. Along with existing therapies, the novel therapies such as anticytokines, small molecule inhibitor, NGF inhibitor, and corticosteroids [81] and other therapies became more prevalent in recent years for the treatment of psoriasis. Although various therapies and drugs are present in the market, still no drugs can permanently cure psoriasis and few of them elicit severe adverse effects. Biological drugs and novel immunological factors act as alternatives to conventional therapies which give a better understanding for functional and immunological pathways of treating psoriasis. These biological drugs show more efficacies with fewer side effects even in long-term usage. Despite their huge cost, it really offers a better alternate for improving the quality of life for patients. Novel drug delivery systems are also found to be effective for the treatment of psoriasis [82].

\section{CONFLICTS OF INTEREST}

All authors have none to declare.

\section{REFERENCES}

1. King-man HO. Psoriasis. Med Diary 2010;15:5.

2. Schön MP, Boehncke WH. Psoriasis. N Engl J Med 2005;352:1899-912.

3. Sarac G, Koca TT, Baglan T. A brief summary of clinical types of psoriasis. North Clin Istanb 2016;3:79-82.

4. Sarıcaoğlu H, Başkan EB. Papüloskuamöz ve eritematöz dermatozlar. ISSUU 2012:12:115-48.

5. Fitzpatrick's Dermatology in General Medicine. Available from: https:// www.accessmedicine.mhmedical.com. [Last accessed on 2018 Jan 10]. 
6. Braun-Falco O, Plewig G, Wolff HH, Burgdorf WHC. Dermatology. $2^{\text {nd }}$ ed. Berlin: Springer-Verlag; 2000. p. 585-607.

7. Christophers E. Psoriasis - epidemiology and clinical spectrum. Clin Exp Dermatol 2001;26:314-20.

8. van de Kerkhof PC. The woronoff zone surrounding the psoriatic plaque. Br J Dermatol 1998;139:167-8.

9. Van De Kerkhof PC. Papulosquamous and Eczematous Dermatoses: Psoriasis. Edinburg: Mosby; 2003. p. 125-49.

10. Gülekon A. Psöriasis ve Benzeri Dermatozlar. İstanbul: Nobel Tıp; 2008. p. 745-60.

11. Bowcock AM, Barker JN. Genetics of psoriasis: The potential impact on new therapies. J Am Acad Dermatol 2003;49:S51-6.

12. Habif T. Clinical Dermatology. Edinburgh: Mosby; 2004. p. 209-40.

13. Sarıfakığlu E. Pustular diseases of the hand. Yeni Tıp Dergis 2010;27:138-41.

14. Erdem H. Psöriatikartritin klinik özellikleri. Romatizma 2000;15:31-8.

15. Yazici CA. Treatment of nail psoriasis. Turkiye Klinikleri J DermatolSpecial Top 2008; 1:31-7.

16. Dombrowski Y, Schauber J. Cathelicidin LL-37: A defense molecule with a potential role in psoriasis pathogenesis. Exp Dermatol 2012;21:327-30

17. Menter A. Guideline of care for the management of psoriasis and psoriatic arthritis. Dermatol 2009;370:272

18. Reisfeld PL. How high is up? Generic prices rise. Cutis 2014;93:6-8.

19. Mason AR, Mason J, Cork M. Topical treatments for chronic plaque psoriasis. Cochrane Database Syst Rev 2013;3:CD005028.

20. Ortonne JP, Humbert P, Nicolas JF, Tsankov N, Tonev SD, Janin A, et al. Intra-individual comparison of the cutaneous safety and efficacy of calcitriol 3 microg g(-1) ointment and calcipotriol 50 microg g(- 1) ointment on chronic plaque psoriasis localized in facial, hairline, retroauricular or flexural areas. Br J Dermatol 2003;148:326-33.

21. Jensen AM, Lladó MB, Skov L, Hansen ER, Larsen JK, Baadsgaard O, et al. Calcipotriol inhibits the proliferation of hyperproliferative CD29 positive keratinocytes in psoriatic epidermis in the absence of an effect on the function and number of antigen-presenting cells. Br J Dermatol 1998;139:984-91.

22. Vissers WH, Berends M, Muys L, van Erp PE, de Jong EM, van de Kerkhof PC, et al. The effect of the combination of calcipotriol and betamethasone dipropionate versus both monotherapies on epidermal proliferation, keratinization and T-cell subsets in chronic plaque psoriasis. Exp Dermatol 2004;13:106-12.

23. Rizova E, Corroller M. Topical calcitriol - studies on local tolerance and systemic safety. Br J Dermatol 2001;144 Suppl 58:3-10

24. Lebwohl M, Menter A, Weiss J, Clark SD, Flores J, Powers J, et al. Calcitriol $3 \mathrm{microg} / \mathrm{g}$ ointment in the management of mild to moderate plaque type psoriasis: Results from 2 placebo-controlled, multicenter, randomized double-blind, clinical studies. J Drugs Dermatol 2007;6:428-35.

25. Goodfield M, Kownacki S, Berth-Jones J. Double-blind, randomised, multicentre, parallel group study comparing a 1\% coal tar preparation (Exorex) with a 5\% coal tar preparation (Alphosyl) in chronic plaque psoriasis. J Dermatolog Treat 2004;15:14-22.

26. Tzaneva S, Hönigsmann H, Tanew A. Observer-blind, randomized, intrapatient comparison of a novel $1 \%$ coal tar preparation (Exorex) and calcipotriol cream in the treatment of plaque type psoriasis. $\mathrm{Br} \mathrm{J}$ Dermatol 2003;149:350-3.

27. Weinstein GD, Koo JY, Krueger GG, Lebwohl MG, Lowe NJ, Menter MA, et al. Tazarotene cream in the treatment of psoriasis: Two multicenter, double-blind, randomized, vehicle-controlled studies of the safety and efficacy of tazarotene creams $0.05 \%$ and $0.1 \%$ applied once daily for 12 weeks. J Am Acad Dermatol 2003;48:760-7.

28. Lebwohl M, Ast E, Callen JP, Cullen SI, Hong SR, Kulp-Shorten CL, et al. Once-daily tazarotene gel versus twice-daily fluocinonide cream in the treatment of plaque psoriasis. J Am Acad Dermatol 1998;38:705-11.

29. Freeman AK, Linowski GJ, Brady C. Tacrolimus ointment for the treatment of psoriasis on the face and intertriginous areas. J Am Acad Dermatol 2003;48:564

30. Wilsmann-Theis D, Hagemann T, Dederer H, Wenzel J, Bieber T, Novak N, et al. Successful treatment of acrodermatitis continua suppurativa with topical tacrolimus $0.1 \%$ ointment. Br J Dermatol 2004;150:1194-7.

31. Mrowietz U, Wustlich S, Hoexter G, Graeber M, Bräutigam M, Luger $\mathrm{T}$, et al. An experimental ointment formulation of pimecrolimus is effective in psoriasis without occlusion. Acta Derm Venereol 2003;83:351-3.

32. van de Kerkhof PC, van der Valk PG, Swinkels OQ, Kucharekova M, de Rie MA, de Vries HJ, et al. A comparison of twice-daily calcipotriol ointment with once-daily short-contact dithranol cream therapy: A randomized controlled trial of supervised treatment of psoriasis vulgaris in a day-care setting. Br J Dermatol 2006;155:800-7.

33. Jekler J, Swanbeck G. One-minute dithranol therapy in psoriasis: A placebo-controlled paired comparative study. Acta Derm Venereol 1992;72:449-50.

34. Oostveen AM, Beulens CA, van de Kerkhof PC, de Jong EM, Seyger MM. The effectiveness and safety of short-contact dithranol therapy in paediatric psoriasis: A prospective comparison of regular day care and day care with telemedicine. Br J Dermatol 2014;170:454-7.

35. Housman TS, Rohrback JM, Fleischer AB Jr. Feldman SR. Phototherapy utilization for psoriasis is declining in the United States. J Am Acad Dermatol 2002;46:557-9.

36. Cooper KD, Oberhelman L, Hamilton TA, Baadsgaard O, Terhune M, LeVee $\mathrm{G}$, et al. UV exposure reduces immunization rates and promotes tolerance to epicutaneous antigens in humans: Relationship to dose, CD1a-DR+ epidermal macrophage induction, and langerhans cell depletion. Proc Natl Acad Sci U S A 1992;89:8497-501.

37. Walters IB, Burack LH, Coven TR, Gilleaudeau P, Krueger JG. Suberythemogenic narrow-band UVB is markedly more effective than conventional UVB in treatment of psoriasis vulgaris. J Am Acad Dermatol 1999;40:893-900.

38. Stern RS. Psoralen and ultraviolet a light therapy for psoriasis. N Engl J Med 2007;357:682-90.

39. Anderson KL, Feldman SR. A guide to prescribing home phototherapy for patients with psoriasis: The appropriate patient, the type of unit, the treatment regimen, and the potential obstacles. J Am Acad Dermatol 2015;72:868-780.

40. Feldman SR, Mellen BG, Housman TS, Fitzpatrick RE, Geronemus RG, Friedman PM, et al. Efficacy of the 308-nm excimer laser for treatment of psoriasis: Results of a multicenter study. J Am Acad Dermatol 2002;46:900-6.

41. Gerber W, Arheilger B, Ha TA, Hermann J, Ockenfels HM. Ultraviolet B 308-nm excimer laser treatment of psoriasis: A new phototherapeutic approach. Br J Dermatol 2003;149:1250-8.

42. Schiener R, Brockow T, Franke A, Salzer B, Peter RU, Resch KL, et al. Bath PUVA and saltwater baths followed by UV-B phototherapy as treatments for psoriasis: A randomized controlled trial. Arch Dermatol 2007;143:586-96.

43. Warren RB, Mrowietz U, von Kiedrowski R, Niesmann J, WilsmannTheis D, Ghoreschi K, et al. An intensified dosing schedule of subcutaneous methotrexate in patients with moderate to severe plaquetype psoriasis (METOP): A 52 week, multicentre, randomised, doubleblind, placebo-controlled, phase 3 trial. Lancet 2017;389:528-37.

44. Gottlieb SL, Gilleaudeau P, Johnson R. Response of psoriasis to a lymphocyte-selective toxin (DAB389IL-2) suggests a primary immune, but not keratinocyte, pathogenic basis. Nat Med 1995;1:442.

45. Saurat JH, Stingl G, Dubertret L, Papp K, Langley RG, Ortonne JP, et al. Efficacy and safety results from the randomized controlled comparative study of adalimumab vs. Methotrexate vs. Placebo in patients with psoriasis (CHAMPION). Br J Dermatol 2008;158:558-66.

46. Buccheri L, Katchen BR, Karter AJ, Cohen SR. Acitretin therapy is effective for psoriasis associated with human immunodeficiency virus infection. Arch Dermatol 1997;133:711-5.

47. Tanew A, Guggenbichler A, Hönigsmann H. Photochemotherapy for severe psoriasis without or in combination with acitretin: A randomized, double-blind comparison study. J Am Acad Dermatol 1991;25:682.

48. Lebwohl M, Drake L, Menter A. Consensus conference: Acitretin in combination with UVB or PUVA in the treatment of psoriasis. J Am Acad Dermatol 2001;45:44.

49. Lam J, Polifka JE, Dohil MA. Safety of dermatologic drugs used in pregnant patients with psoriasis and other inflammatory skin diseases. J Am Acad Dermatol 2008;59:295-315.

50. Flytström I, Stenberg B, Svensson A, Bergbrant IM. Methotrexate vs. Ciclosporin in psoriasis: Effectiveness, quality of life and safety. A randomized controlled trial. Br J Dermatol 2008;158:116-21.

51. Sandhu K, Kaur I, Kumar B, Saraswat A. Efficacy and safety of cyclosporine versus methotrexate in severe psoriasis: A study from North India. J Dermatol 2003;30:458-63.

52. Papp K, Bissonnette R, Rosoph L, Wasel N, Lynde CW, Searles G, et al. Efficacy of ISA247 in plaque psoriasis: A randomised, multicentre, double-blind, placebo-controlled phase III study. Lancet 2008;371:1337-42.

53. Schafer PH, Parton A, Gandhi AK, Capone L, Adams M, Wu L, et al. Apremilast, a cAMP phosphodiesterase-4 inhibitor, demonstrates anti-inflammatory activity in vitro and in a model of psoriasis. Br J Pharmacol 2010;159:842-55. 
54. Gottlieb AB, Strober B, Krueger JG, Rohane P, Zeldis JB, Hu CC, et al. An open-label, single-arm pilot study in patients with severe plaque-type psoriasis treated with an oral anti-inflammatory agent, apremilast. Curr Med Res Opin 2008;24:1529-38.

55. Papp K, Cather JC, Rosoph L, Sofen H, Langley RG, Matheson RT, et al. Efficacy of apremilast in the treatment of moderate to severe psoriasis: A randomised controlled trial. Lancet 2012;380:738-46.

56. Papp KA, Kaufmann R, Thaçi D. Efficacy and safety of apremilast in subjects with moderate to severe plaque psoriasis: Results from a phase II, multicenter, randomized, double-blind, placebo-controlled, parallel-group, dose-comparison study. J Eur Acad Dermatol Venereol 2013;27:376

57. Feldam S. Treatment of psoriasis. J Eur Acad Dermatol Venereol 2017:31:205.

58. Yost J, Gudjonsson JE. The role of TNF inhibitors in psoriasis therapy: New implications for associated comorbidities. F1000 Med Rep 2009; $1: 30$

59. Anderson PJ. Tumor necrosis factor inhibitors: Clinical implications of their different immunogenicity profiles. Semin Arthritis Rheum 2005;34:19-22

60. Reich K, Nestle FO, Papp K, Ortonne JP, Evans R, Guzzo C, et al. Infliximab induction and maintenance therapy for moderate-tosevere psoriasis: A phase III, multicentre, double-blind trial. Lancet 2005;366:1367-74

61. Weinberg JM. An overview of infliximab, etanercept, efalizumab, and alefacept as biologic therapy for psoriasis. Clin Ther 2003;25:2487-505.

62. Menter A, Tyring SK, Gordon K, Kimball AB, Leonardi CL, Langley RG, et al. Adalimumab therapy for moderate to severe psoriasis: A randomized, controlled phase III trial. J Am Acad Dermatol 2008;58:106-15.

63. Reich K, Burden AD, Eaton JN, Hawkins NS. Efficacy of biologics in the treatment of moderate to severe psoriasis: A network meta-analysis of randomized controlled trials. Br J Dermatol 2012;166:179-88.

64. Rider P, Carmi Y, Cohen I. Biologics for targeting inflammatory cytokines, clinical uses, and limitations. Int $\mathrm{J}$ Cell Biol 2016;2016:9259646.

65. YeP, RodriguezFH, Kanaly S, Stocking KL, Schurr J, Schwarzenberger P, et al. Requirement of interleukin 17 receptor signaling for lung CXC chemokine and granulocyte colony-stimulating factor expression, neutrophil recruitment, and host defense. J Exp Med 2001;194:519-27.

66. Wada Y, Cardinale I, Khatcherian A, Chu J, Kantor AB, Gottlieb AB, et al. Apilimod inhibits the production of IL-12 and IL-23 and reduces dendritic cell infiltration in psoriasis. PLoS One 2012;7:e35069.

67. Wada Y, Lu R, Zhou D, Chu J, Przewloka T, Zhang S, et al. Selective abrogation of th1 response by STA-5326, a potent IL-12/IL-23 inhibitor. Blood 2007; 109:1156-64.

68. Hueber W, Patel DD, Dryja T, Wright AM, Koroleva I, Bruin G, et al. Effects of AIN457, a fully human antibody to interleukin-
17A, on psoriasis, rheumatoid arthritis, and uveitis. Sci Transl Med 2010;2:52ra72

69. Ren V, Dao H Jr. Potential role of ixekizumab in the treatment of moderate-to-severe plaque psoriasis. Clin Cosmet Investig Dermatol 2013;6:75-80

70. Kormeili T, Lowe NJ, Yamauchi PS. Psoriasis: Immunopathogenesis and evolving immunomodulators and systemic therapies; U.S. Experiences. Br J Dermatol 2004;151:3-15.

71. Chamian F, Lowes MA, Lin SL, Lee E, Kikuchi T, Gilleaudeau P, et al. Alefacept reduces infiltrating $\mathrm{T}$ cells, activated dendritic cells, and inflammatory genes in psoriasis vulgaris. Proc Natl Acad Sci U S A 2005; $102: 2075-80$

72. Torres T, Filipe P. Small molecules in the treatment of psoriasis. Drug Dev Res 2015;76:215-27.

73. Claveau D, Chen SL, O'Keefe S, Zaller DM, Styhler A, Liu S, et al. Preferential inhibition of $\mathrm{T}$ helper 1 , but not $\mathrm{T}$ helper 2 , cytokines in vitro by L-826,141 [4-[2-(3,4-bisdifluromethoxyphenyl)-2-[4(1,1,1,3,3,3-hexafluoro-2-hydroxypropan-2-yl)-phenyl]-ethyl]3methylpyridine-1-oxide], a potent and selective phosphodiesterase 4 inhibitor. J Pharmacol Exp Ther 2004;310:752-60.

74. Houslay M.D, Schafer P, Zhang KY. Keynote review: Phosphodiesterase-4 as a therapeutic target. Drug Discov Today 2005;22:1503-19.

75. Ortiz-Ibáñez K, Alsina MM, Muñoz-Santos C. Tofacitinib and other kinase inhibitors in the treatment of psoriasis. Actas Dermosifiliogr 2013;104:304-10.

76. Ryan C, Abramson A, Patel M, Menter A. Current investigational drugs in psoriasis. Expert Opin Invest Drugs 2012;4:304-10.

77. Schieven GL. The biology of $\mathrm{p} 38$ kinase: A central role in inflammation. Curr Top Med Chem 2005;5:921-8.

78. Johansen C, Vinter H, Soegaard-Madsen L, Olsen LR, Steiniche T, Iversen L, et al. Preferential inhibition of the mRNA expression of $\mathrm{p} 38$ mitogen-activated protein kinase regulated cytokines in psoriatic skin by anti-TNF $\alpha$ therapy. Br J Dermatol 2010;163:1194-204.

79. Borie DC, Si MS, Morris RE, Reitz BA, Changelian PS. JAK3 inhibition as a new concept for immune suppression. Curr Opin Investig Drugs 2003;4:1297-303.

80. Pesu M, Candotti F, Husa M, Hofmann SR, Notarangelo LD, O'Shea JJ, et al. Jak3, severe combined immunodeficiency, and a new class of immunosuppressive drugs. Immunol Rev 2005;203:127-42.

81. EL-Gizaway S, Fadel M, Mourad B, EL-Zahraa F, Elnaby A. Betamethasone dipropionate gel for the treatment of localized plaque psoriasis. Int J Pharm Pharm Sci 2017;9:173-82.

82. Soliman GM, Osman SK, Hamdan AM. Preparation and evaluation of anthralin biodegradable nanoparticles as a potential delivery system for the treatment of psoriasis. Int J Pharm Pharm Sci 2015;7:36-40. 